\title{
Wild North Island Robins (Petroica longipes) respond to Prey Animacy
}

\author{
Alexis Garland $^{1 *}$ and Jason Low ${ }^{1}$ \\ ${ }^{1}$ Victoria University of Wellington \\ *Corresponding author (Email: dralexisgarland@gmail.com) \\ Citation - Garland, A., \& Low, J. (2014). Wild north island robins (Petroica longipes) respond to prey animacy. \\ Animal Behavior and Cognition, 1(3), 352-367. doi: 10.12966/abc.08.10.2014
}

\begin{abstract}
North Island robins of New Zealand are a food hoarding species, which is unique in that they almost exclusively cache highly perishable hunted insects for later retrieval. In order to do so, they either kill and dismember or paralyze their prey for caching, depending on the prey size and kind. The present study comprises two experiments, using a Violation of Expectancy (VoE) paradigm to examine variation in search behavior response to different prey conditions. The first experiment presents three different types of prey (mealworms, earthworms and locusts) in expected (present) and unexpected (absent) conditions. The second experiment presents prey in varying states of animacy (alive and whole, dead and whole, dead and halved, and an inanimate stick) and reveals prey in expected (same state) or unexpected (differing state) conditions. While robins did not respond with differential search times to different types of unexpectedly missing prey in Experiment 1, in Experiment 2 robins searched longer in conditions where prey was found in a differing state of animacy than initially shown. Robins also searched longer for prey when immediately consuming retrieved prey than when caching retrieved prey. Results indicate that North Island robins may be sensitive to prey animacy upon storage and retrieval of insect prey; such information could play a role in storage, pilfering and retrieval strategies of such a perishable food source.
\end{abstract}

Keywords - New Zealand robin, Caching, Food hoarding, Animacy, Prey

Caching species more often store food that has a relatively long shelf-life, such as nuts or seeds (Sherry, 1985), rather than highly perishable food like flesh from living prey or soft fruits. In this respect, North Island, and New Zealand robins in general, are unique in that the food they hoard throughout their territories almost exclusively consists of insects that have been hunted and then stunned or killed (and sometimes partitioned if large) before caching (Menzies \& Burns, 2008; Van Horik \& Burns, 2007). Due to the high perishability of the food stored, robins retrieve stores within 1-3 days of them being made (Powlesland, 1980). In the cognitive experiments presented here with North Island robins, mealworms, earthworms and locusts were used as prey both in spontaneous Violation of Expectancy (VoE) tasks. A small handful of other studies have used living prey such as crickets (Spelke \& Kinzler, 2007) and fruit flies (Uller, Jaeger, Guidry, \& Martin, 2003) or in some cases a given number of conspecifics (Agrillo, Dadda, Bisazza, 2007; Agrillo, Dadda, Serena, \& Bisazza, 2008; Dadda, Piffa, Agrillo, \& Bisazza, 2009; McComb, Packer, \& Pusey, 1994) as the countable 'items' in a numerical discrimination task, but the larger portion of such experiments were done with inanimate objects such as plant-based food (e.g., Beran, 2001, 2007; Santos, Barnes, \& Mahajan, 2005; Rugani, Regolin, \& Vallortigara, 2011; Perdue, Talbot, Stone, \& Beran, 2012) or sometimes tokens (e.g., Addessi, Crescimbene, \& Visalberghi, 2008; Beran, Evans, \& Hoyle, 2011; Chen, Lakshminarayanan, \& Santos, 2006).

The unique nature of New Zealand robins' storage of hunted prey - live insects - rather than completely inanimate food objects (such as seeds) presents an unusual context which begs a closer look at 
the boundary between object and agent. Robins' naïve, fearless approach of mammals such as humans (Menzies \& Burns, 2008) makes them the ideal subject with which to begin to examine this topic in a wild population. In previous studies (Armstrong, Garland, \& Burns, 2012; Garland, Low, \& Burns, 2012; Hunt, Low \& Burns, 2008) focusing on quantities of 'items', the 'objects' presented in tasks were living prey (mealworms). These paradigms are formed on the basis of a theory that assumes that the objects responded to are characterized by, and limited to, properties specific only to inanimate objects; persisting over occlusion and subject to laws of physics such as gravity and motion (Spelke, 2000; Spelke \& Kinzler, 2007). However, whether such attributions are indeed restricted to agents (Csibra, Gergely, Biro Koós, \& Brockbank, 1999) and innate systems based on cues such as the properties mentioned above (Csibra \& Gergely, 1998; Gergely \& Csibra, 2003), or experience-based systems dependent on prior social interaction (Guajardo \& Woodward, 2004; Meltzhoff \& Moore 1994; Woodward, 1999;), or somewhere between the two (Biro \& Leslie, 2007), is a matter of some debate in terms of findings and interpretation.

Whereas agency is not the only salient cue to foraging, it - and components such as motion - is particularly salient to feeding on living things, in contrast to feeding on seeds or plants, where movement and animacy of the food item are unlikely to come into play. For animals, in order to successfully adapt hunting strategies for different living prey, behavioral responses to that prey must of course be mediated by characteristics of that prey: an agent rather than an object. Whether some basic representation of agency is used, or behavioral rules are developed by experience and tailored to differing prey behavior (e.g., movement for escape) - it appears that for robins, prey is first animate, and then strategically killed and stored as objects. This study aims to make a first start investigating the boundary and transition between the animate-inanimate distinction in such prey, and how responses of North Island robins might be influenced by expectations specific to the type of prey, or the animacy state of prey.

Arguably, the most important function of an agency system is agency detection - the ability to discriminate between things capable of goal-directed action and self-propulsion and things that are not; an ability that appears to have its own dedicated neural network (Gobbini et al., 2011). There are obvious costs and benefits resulting from the ability (or failure) of an animal to successfully and reliably detect and respond to agency. This is particularly true in reference to predator-prey interactions, where life and reproduction often depend on quickly detecting animacy in surroundings in order to identify threats or opportunities (Barrett, 2005; Barrett \& Behne, 2005). Over the course of time, it is exactly this interaction of success and failure in recognition that shapes the evolution of such detection systems present in nearly all species (Barrett \& Behne, 2005). This very basic categorization of the world - animate/agent and inanimate/object - and the resultant ability to respond differently to each category (Barrett \& Behne, 2005; Spelke \& Kinzler, 2007) allows species to scaffold more complex behaviors upon such a framework; responding with a fine-tuned suite of behaviors geared toward specific prey, like bee-eaters (Watve et al., 2002), or in the case of human infants, the ability to build entire hierarchies of subcategories with associated representations and contexts (Carey, 2009).

Causality and self-propelled motion are key features of identifying animacy. In a habituation/dishabituation experiment, for example, when exposed to videos either with natural causal sequences (such as a hand picking up an item and carrying it off screen), or unnatural sequences (where the hand does not pick up the item but both move off screen), chimpanzees (Pan troglodytes) looked significantly longer at unnatural physical events than natural ones (O'Connell \& Dunbar, 2005). Newly hatched domestic chickens (Gallus gallus) also show sensitivity for self-propelled causal agency (Mascalzoni, Regolin, \& Vallortigara, 2010). When shown objects that display either self-propelled or externally caused motion, they prefer to associate with self-propelled objects as companions. According to Rakison and Poulin-Dubois (2001), drawing on patterns emergent from infant research on representation and categorization of animacy, there are seven characteristic properties of the animateinanimate distinction, all of which are related to physical or psychological causality. Their theory proposes that animates display 1) self-propelled onset of motion, rather than externally caused, 2) a smooth (instead of irregular) line of trajectory 3) causal action (at a distance and irrespective of physical contact), 4) contingent (reciprocal) patterns of interaction, 5) an agent type of causal role rather than 
recipient, 6) purposeful, goal-directed action, 7) the influence of an intentional mental state rather than accidental. In a review of research based on visual interpretation of very simple two-dimensional shapes interacting in either a causal or self propelled way, Scholl and Tremoulet (2000) conclude that the visual system involves a mechanism that focuses on features like causality and animacy in objects. Such a system would inform causal and social structure of surroundings, the same way that the visual system has a mechanism focusing on physical features in order to inform 3-dimensional structure of the surrounding world.

Agency detection and perception of varying states of animacy is perhaps unsurprisingly underinvestigated in the context of caching live prey in the wild, given the relative rarity of this behavior. Few species depend on either killing, paralyzing, or occasionally even maintaining live prey and caching it for some period of time. Leopards often hang carcasses in trees or sometimes bury them, wolves and foxes sometimes bury whole or partial carcasses, and some species of moles and shrews store earthworms in 'knots' (balled up clumps) underground (Vander Wall, 1990). Some raptors (e.g., Collopy, 1977; Holthuijzen , 1990; Korpimaki, 1987; Oksanen, Oksanen, \& Fretwell, 1985; Solheim, 1984), crows (e.g., Berrow, Kelly, \& Myers, 1992; James \& Verbeek, 1985) and ravens (e.g., Bugnyar, Stoewe, \& Heinrich, 2007; Heinrich \& Pepper, 1998) will cache small mammals, pieces of carrion, mussels or clams under certain conditions, such as raising a nestling, seasonal prey surplus and shortage, or tidal availability.

The majority of caching birds however, appear to cache less perishable plant-based food such as seeds, although New Caledonian crows - who also show some evidence of caching, according to Kenward et al. (2006) - are unusually skilled at using tools to poke insect larvae out of trees (Bluff, Weir, Rutz, Wimpenny, \& Kacelnik, 2007; Taylor, Hunt, \& Gray, 2012; Taylor, Hunt, Holzhaider, \& Gray, 2007). Scrub Jays (Aphelocoma coerulescens) in experimental conditions will recover caches of highly perishable worms or crickets only after a shorter interval, and switch to recovering less perishable peanuts after longer intervals at which point perishable worms are unlikely to be palatable (Clayton \& Dickinson, 1999; Clayton, Emery, \& Dickinson, 2006). Scrub jays also sometimes cache insects or fruit in addition to seeds in the wild (Emery \& Clayton, 2004), although the exact extent to which Scrub Jay caches in the wild are composed of insect matter seems less clear (Sherry, 1985). Accurately judging the time of death is important to knowing the perishability of the food source. Being able to distinguish paralysis from death (and hunt accordingly) could potentially allow individuals to more accurately gauge and adapt storage strategies in order to lengthen the shelf life of a food.

Prey preference and selection is often based on movement - biological motion (Johansson, 1973). Domestic chicks (Gallus gallus) for example, prefer to peck at insect-like elongated stimuli moving in a direction orthogonal to their longer axis (i.e., 'sideways' rather than 'forward') in a computer simulation test (Clara, Regolin, Vallortigara, \& Rogers, 2009). Newly hatched chicks also show a preference to approach and stay next to objects with self-propelled motion, and point-light animations exhibiting biological motion patterns, such as a hen or a cat, rather than a random sequence (Vallortigara, Regolin, \& Marconato, 2005; Mascalzoni, Regolin \& Vallortigara, 2010). Grey partridge chicks' (Perdix perdix) food preference is influenced by color (yellow/green), size (large but able to be swallowed whole), and movement (preferring living to dead insects whether fast or slow moving) (Moreby, Aebischer, \& Southway, 2006).

We used a within-subjects design across two experiments to test whether robins were sensitive to general Violations of Expectancy (VoE) and prey type preference (Experiment 1), as well as the state of animacy of prey (Experiment 2). Previous research (Hunt et al., 2008) found that robins search longer if a smaller quantity of worms is found than were originally hidden (e.g., 4 are hidden, and only 2 are found). In Experiment 1, we investigated whether they also searched longer when no prey was found. Whereas the previous study would indicate a likelihood to persist in searching, given the setting, (native forest in their own territory) and surrounding natural resources, when finding no bait at all, they could potentially simply hunt in the immediate area instead of persisting in searching. Three different types of prey are presented, including mealworms (Tenebrio molitor larvae), earthworms (Eisenia andrei), and locusts (Locusta migratoria). Each prey type was presented in one congruent trial, where the same type of insect placed in the box was uncovered by the bird, and one incongruent trial, where no insect was found after 
one was visibly placed inside the box. It was expected that in all three cases, search times for incongruent trials will be longer than responses to congruent trials. This experiment tested basic responses to a VoE design to establish firstly whether a differential response is present in robins (if search times were significantly longer or shorter when an insect is not found), and secondly whether such a differential response varies depending on the type of insect hidden. In Experiment 2, only mealworm prey was presented, but in varying states of animacy: live (and whole), dead (and whole), and halved. In some conditions a small twig with roughly the same coloration and dimensions of a mealworm was used as a completely inanimate object. This experiment aimed to discern whether robins would search for a different amount of time when the animacy state of prey altered, and what kind of alteration of state might result in a longer or shorter search time, which would indirectly indicate a sensitivity to the state of animacy in cached prey.

\section{Method}

\section{Subjects}

A total of 11 wild adult North Island robins (Petroica longipes) participated in this study, with each participating in both experiments. Each subject was identified with the unique combination of colored bands on the bird's legs, and prior experimental history. Robins are non-migratory songbirds that live in mated pairs on established territories, typically raising 2-3 clutches per season, which then disperse by winter (Menzies \& Burns, 2008). In addition to hunting and caching insects, pairs also pilfer a substantial portion of prey from mates (Burns \& Van Horik, 2007; Van Horik \& Burns, 2007). Of the 11 adult birds, 9 were male and 2 were female. Because most were banded as adults, exact ages are not known, but based on banding dates, their minimum ages at the time of the study ranged from at least three to five years old. This population of robins is found in Zealandia Sanctuary, a 225ha fenced section of regenerating native bush, located in Wellington, New Zealand. Birds along a small section of the northeastern portion of the sanctuary, within proximity of paths, were targeted for this study. Although birds within the sanctuary are free to disperse beyond the fence (and return), the fence is designed to prevent introduced mammals such as rats, cats, or stoats, which threaten breeding populations of native species, which are monitored within the sanctuary.

Zealandia is an attraction open to the public, and as such, while these wild robins do not encounter predatory mammals within the sanctuary, robins with territories intersected by walking paths particularly in the northern end of the forest near the entrance - will frequently observe and encounter human visitors walking through. Visitors are banned from providing food of any sort to birds, so while some species are provisioned indirectly by sanctuary staff (like the supplemental food provided at stations to Kaka and Hihi), robins themselves receive no supplementary food whatsoever. Robins in this study had participated in prior choice-task experiments, and as such had experience receiving food (mealworms) from an experimenter. Robins, females in particular, frequently kleptoparasitise caches made by others (Van Horik \& Burns, 2007), and as such, are motivated to attend to the contents of experimental caches made by humans.

\section{Apparatus and Materials}

Trials were performed by presenting subjects with mealworms (Tenebrio molitor larvae), earthworms (Eisenia Andrei), locusts (Locusta migratoria), or a small stick (roughly analogous in size and color to a mealworm). Earthworms and orthoptera (the order including weta and locusts) are a natural part of New Zealand robins' diet (Menzies \& Burns, 2008), and mealworm larvae is an easily obtained larval-stage beetle that is similar to other types of larvae robins may find hunting on the forest floor. These insects were placed individually into a wooden encasement designed for Violation of Expectancy (VoE) testing (see Figure 1). The box measured $9.5 \mathrm{~cm}$ wide, $4 \mathrm{~cm}$ tall, and $17 \mathrm{~cm}$ long, with a thin, particleboard slider protruding from one side that extends out when pulled and slides into the box when 
pushed. This slider attached to an upper compartment comprising a clear Petri dish measuring $6 \mathrm{~cm}$ in diameter mounted on the inside of the box. The visible side of the Petri dish in the upper compartment was covered in opaque black tape so that the only the contents of the lower well were visible when this sliding compartment was pushed into the box. A hole measuring $6 \mathrm{~cm}$ in diameter on the surface of the box allowed the subject to see either the upper sliding compartment $(1 \mathrm{~cm}$ deep), or the lower well when the upper compartment was slid into the box. The well below was accessible when the sliding compartment pulled out fully, and lined with the same type and size plastic petri dish. The plastic lining of each well served to prevent the mealworms from being able to climb the rough wooden surface of the encasement. The well was covered with a circular brown leather flap approximately $7 \mathrm{~cm}$ across. Insect prey were placed in the apparatus with stainless steel tweezers, to enable the clearest possible view of the prey.

\section{Procedure}

In both experiments, the VoE box was used with both the upper and lower compartments filled, regardless of whether the outcome was expected (items were the same) or unexpected (items differed). Birds were presented with between one and eight trials per day, depending on interest and engagement. Birds that flew off to another part of the territory, engaged in other activities such as hunting, bathing, provisioning or territorial defense were not presented to or presentations were terminated and resumed another day. In that manner, all robins observed prey being dropped only into the lower compartment, and were always able to retrieve it only from the upper compartment. Given this method, any difference in response due to a perceived difference in depth of the well, insect noise, or any other cues not apparent to the experimenter, were consistently accounted for and occurred both in expected and unexpected events.

Robins' experience with a quantity discrimination choice-task (Garland, Low \& Burns, 2012), which involved pulling a leather flap off of a wooden block with a well, meant structurally the block and leather flap were familiar - and thus easily removed with no training or further familiarization. No training or additional familiarization was used at any time prior to or throughout experimentation. Initial familiarization (prior to this study) with the flap and platforms was minimal. Robins spend the majority of their time hunting on the forest floor, turning over leaves in search of insects. As such, pulling the leather flap from a small wooden platform was a very simple extension of their natural behavior, adopted typically within a very short period of exposure to the materials (well under $30 \mathrm{~min}$, on average). Subjects were tested individually, within the bounds of their natural territories, and did not observe other individuals completing the tasks. Trials were recorded on digital video camera and then analyzed to assess search time spent post-trial, and the number of beak-to-apparatus contacts (either the box or flap), or 'pecking.' These results were analyzed using within-subjects repeated measures ANOVAs, examining each of the two dependent variables separately.

Experiment 1: Prey type. Robins were shown six different hiding events with order controlled using a Latin Square, such that each bird was presented with a unique randomized order, of which three were congruent (the same type of insect that was dropped in was found) and three were incongruent (no insect was found) (see Table 1).

Table 1

\begin{tabular}{|c|c|c|}
\hline \multicolumn{3}{|c|}{ Experiment 1} \\
\hline Condition & Viewed Entering Box & Revealed \\
\hline 1 & Living Locust & Living Locust \\
\hline 2 & Living Locust & Empty \\
\hline 3 & Living Mealworm & Living Mealworm \\
\hline 4 & Living Mealworm & Empty \\
\hline 5 & Living Earthworm & Living Earthworm \\
\hline 6 & Living Earthworm & Empty \\
\hline
\end{tabular}




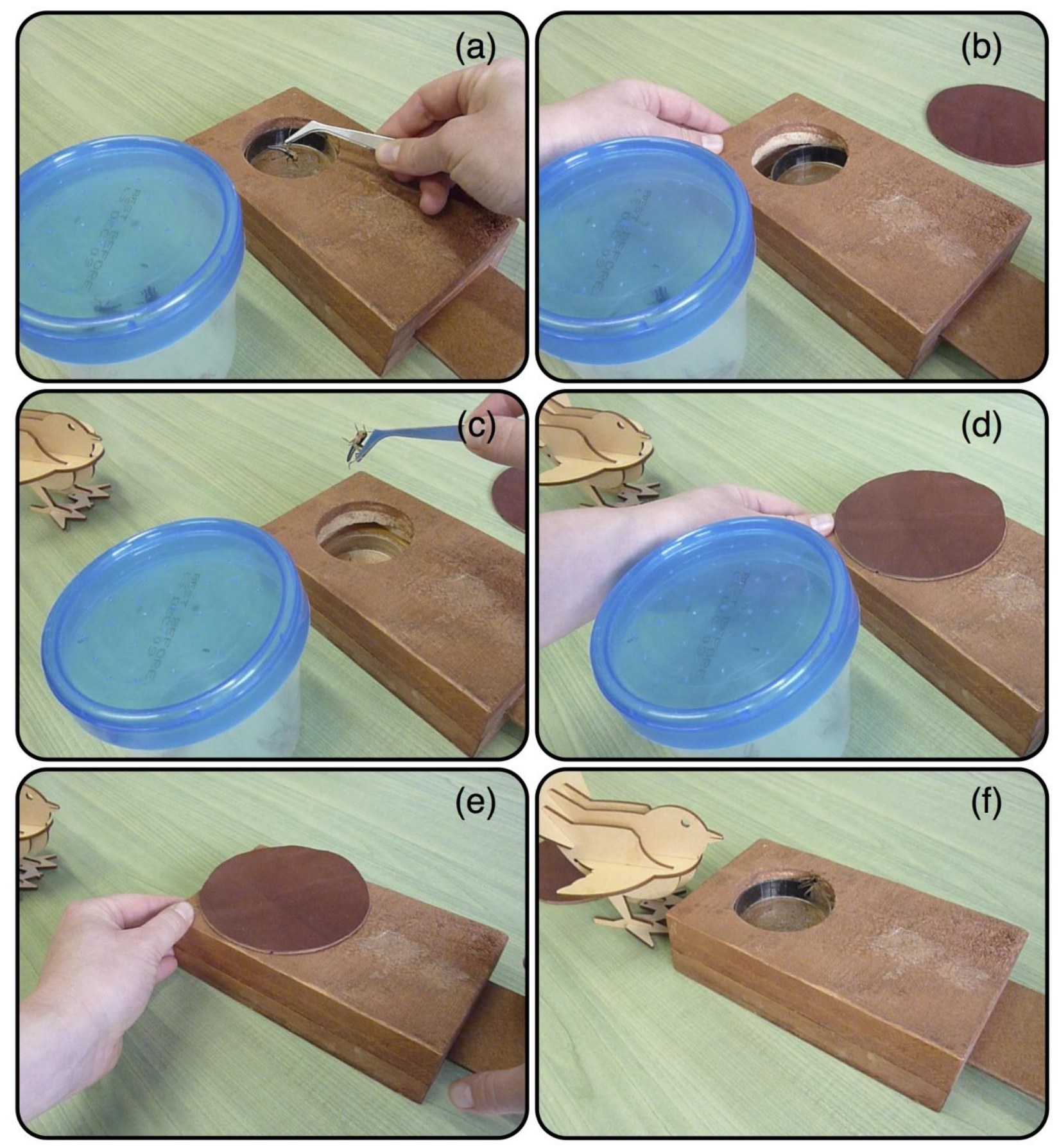

Figure 1. The VoE apparatus: Out of view of the bird, in the upper compartment, (a) insects are placed inside and (b) the compartment is slid out, hiding it. In view of the bird, in the lower compartment (c) insects are placed inside (d) the lid covers the well, (e) the drawer is slid in, and (f) the bird allowed to access the upper compartment.

The sliding compartment of the VoE box was first loaded with an insect (mealworm, earthworm, or locust) intended for the robin to find, out of view of the experimental subject. The sliding compartment was then pulled fully out so that the contents were not visible. In the events where nothing is found, no insect was pre-loaded into this compartment. Within the subject's natural territory, the experimenter then located and attracted the attention of the subject (by clapping and whistling). When the subject was within $1-3 \mathrm{~m}$ of the experimenter, she knelt, and placed the $\mathrm{VoE}$ box on the ground between herself and the bird 
in a spot with a clear line of sight (no branches or leaves between the VoE box and the subject), and where conflict with neighbors was unlikely to occur (away from the territory border). The trial did not proceed until the subject was sitting less than $2 \mathrm{~m}$ of the VoE box and clearly attending - looking in the direction of the experimenter, following movements of the experimenter and tweezers. The VoE box was then placed so that it was clearly visible to the subject, within a 1-3m distance of the robin's viewing position. A clear plastic container housing a number of the insects about to be dropped into the VoE box is set next to the box, in order that the robin sees the insects actively moving about inside the container. One live insect was taken with tweezers and first displayed clearly for approx. 4s by holding it directly over the well, in order to give the robin the opportunity to clearly see the type of insect and its movement. The insect was then released from the tweezers in clear view of the robin, and dropped into the empty bottom compartment of the VoE box, and subsequently covered with the leather flap. The hidden sliding compartment drawer was then pushed closed, so the robin found only what was in the upper compartment (either empty, or with the same type of insect that was seen dropped in). Lastly, robins were given the opportunity to approach and uncover the well, and retrieve a combination of worms either congruent or incongruent with the category of worms they observed being added or removed. If robins flew away to cache the insect they were allowed to re-approach and continue searching the apparatus if they returned within 20s (caching nearby typically takes less than this amount of time); the time spent caching was not included as active search time in the analysis.

Experiment 2: Prey animacy. In this experiment, robins were shown eight different hiding events with mealworm prey hidden and then found in different states (live, dead, halved), or in some cases substituted by a small stick (see Table 2). Of these, two were found congruent with what was hidden (e.g., Live-live, dead-dead), two were halved (live-half, dead-half), two were found living (dead-live, stick-live), and two were found inert (live-dead, live-stick).

Table 2

Congruent and Incongruent Conditions Presented in Experiment 2, Altering Insect Animacy

\begin{tabular}{cll}
\hline & \multicolumn{1}{c}{ Experiment 2 } \\
\hline Condition & Viewed Entering Box & Revealed \\
\hline 1 & Living Mealworm & Living Mealworm \\
3 & Living Mealworm & Dead Mealworm \\
4 & Living Mealworm & Half Mealworm \\
5 & Dead Mealworm & Living Mealworm \\
6 & Dead Mealworm & Dead Mealworm \\
7 & Dead Mealworm & Half Mealworm \\
8 & Living Mealworm & Stick \\
\hline & Stick & Living Mealworm \\
\hline
\end{tabular}

Order of exposure was controlled using a Latin Square in order to create a unique random order for trial exposure for each subject. The sliding compartment of the $\mathrm{VoE}$ box was first loaded with insect (or stick) intended for the robin to find, out of view of the experimental subject, and the sliding compartment was pulled fully out so that the contents were not visible. As in Experiment 1, the VoE box was then placed so that it was clearly visible to the subject, within a 1-3m distance of the robin's viewing position. Again, the clear plastic container containing insects was visible to the robin prior to and during the trial. An insect was taken with tweezers and first displayed clearly for approx. 4s by holding it directly over the well, in order to give the robin the opportunity to clearly see the type of insect and its state (active movement or inert). It was then dropped in clear view of the robin into the empty bottom compartment of the $\mathrm{VoE}$ box, and subsequently covered with the leather flap. The hidden sliding compartment drawer was then pushed closed, so the robin found only what was in the upper compartment (either alive or inert). Lastly, robins were given the opportunity to approach and uncover the well, and retrieve a combination of worms either congruent or incongruent with the category of worms they observed being added or removed. 


\section{Results}

A video analysis was performed looking at two different measures of response behavior. For both experiments, the first dependent variable analyzed was active search time (ST) - the total amount of time (in seconds) the robin spent actively examining the apparatus or leather cover. The second was pecking frequency (PF) - the number of times the subject pecked with its beak at any part of the apparatus (within the aforementioned search time). The data was also analyzed jointly (across both Experiments 1 and 2) looking at the destination of the prey obtained by the robin, and whether it was eaten immediately or removed for caching or provisioning, to examine any differences that might be seen in response as a result.

Experiment 1: Prey type. This experiment involved hiding events using three types of prey; mealworms, earthworms and locusts. An experimenter displayed an event where the robin found prey that was either congruent with the prey seen being dropped into the box, or found the box empty.

Behavioral response measure 1: Search time. A within-subjects repeated measures ANOVA with search time as the dependent variable was used to compare means between conditions, including congruence (congruent and incongruent) and insect type (locust, mealworm, earthworm). Overall, mean search time for congruent trials was lower $(21.88 \mathrm{~s} \pm 2.69 \mathrm{~s})$ than for incongruent trials $(53.88 \mathrm{~s} \pm 5.74 \mathrm{~s})$. There was a significant main effect of congruence $(F(1,10)=19.567, p=0.001)$, but no significant effect of insect type $(F(2,9)=2.707, p=0.091)$, and no significant interaction between congruence and insect type $(F(2,9)=0.628, p=0.544)$. Pairwise comparisons of insect type in this analysis show that there is no significant difference $(p=0.434)$ in search time variation between locust (mean congruent $=21.64 \mathrm{~s} \pm$ $5.38 \mathrm{~s}$, mean incongruent $=55.36 \mathrm{~s} \pm 6.25 \mathrm{~s}$ ) and mealworm (mean congruent $=31.45 \mathrm{~s} \pm 4.24 \mathrm{~s}$, mean incongruent $=56.55 \mathrm{~s} \pm 12.66 \mathrm{~s})$. There is also no significant difference in search time variation $(p=0.098)$ between locust and earthworm (mean congruent $=12.55 \mathrm{~s} \pm 2.15 \mathrm{~s}$, mean incongruent $=49.73 \mathrm{~s} \pm 10.69 \mathrm{~s}$ ), but there is a significant difference in search time variation between mealworm and earthworm prey $(p=$ 0.042) (see Figure 2a).

Behavioral response measure 2: Pecking frequency. A within-subjects repeated measures ANOVA was also conducted with pecking frequency as the dependent variable, again with congruence (congruent and incongruent) and insect type (locust, mealworm, earthworm) as independent variables. Overall, mean pecking frequency for congruent trials was lower $(2.97 \pm 0.67$ pecks) than for incongruent trials $(5.70 \pm 0.94$ pecks $)$. There was no significant effect either for congruence $(F(1,10)=3.445, p=$ $0.093)$, insect type $(F(2,9)=1.126, p=0.344)$, or interaction between congruence and insect type $(F(2$, $9)=0.776, p=0.474)$. Pairwise comparisons of insect type in this analysis show that there is no significant difference $(p=0.496)$ in pecking frequency variation between locust (mean congruent $=3.27$ \pm 1.05 , mean incongruent $=7.09 \pm 1.65$ ) and mealworm (mean congruent $=3.36 \pm 1.11$, mean incongruent $=5.09 \pm 1.73)$. There is also no significant difference in pecking frequency variation $(p=$ 0.139 ) between locust and earthworm (mean congruent $=2.27 \pm 1.38$, mean incongruent $=4.91 \pm 1.58$ ), or between mealworm and earthworm prey $(p=0.432)$ (see Figure $2 b$ ).

Experiment 2: Prey animacy. This experiment involved hiding events using only one type of prey (mealworms), displayed in various states (alive, dead, halved), or a small stick of an analogous size. An experimenter displayed an event where the robin found prey that was either in a congruent state or in an incongruent state with the prey seen being dropped into the box. Prey was found either in the same state it was hidden (live-live, dead-dead); found alive after being dropped in inanimate (dead-live, sticklive), found inanimate after being dropped in alive (live-dead, live-stick), or found halved (and dead) after being dropped in whole (live-half, dead-half).

Repeated measures ANOVAs were used, first with search time as the dependent variable, and secondly with pecking frequency. Congruence (congruent and incongruent) and mealworm state were variables examined in each analysis. Mealworm state was analyzed three ways. First, grouping the eight conditions into four groups of trial type: congruent (e.g., live-live, dead-dead), found living (dead-live, stick-live), halved (live-half, dead-half), and found inert (live-dead, live-stick). Second, all eight 
conditions are individually analyzed (including pairwise comparisons). Third, grouping the eight conditions into two groups: congruent/positively incongruent - where prey was found either in the same, whole state, or in better condition than initially (live-live, dead-dead, dead-live, stick-live), and negatively incongruent - where prey was found only partial, or in worse condition than initially (live-half, dead-half, live-dead, live-stick).
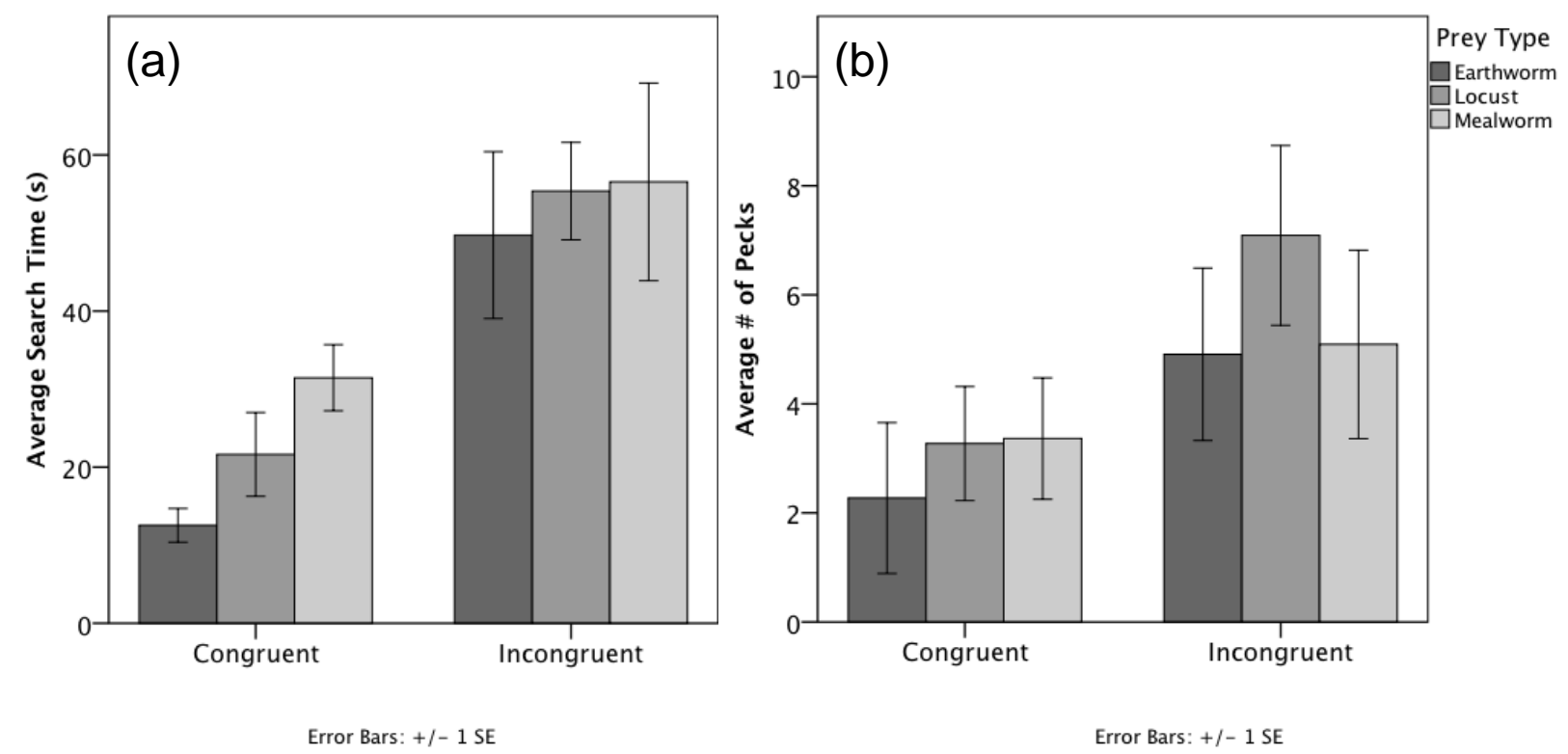

Figure 2. Experiment 1 (Prey type) - Average response in search and attendance time and number of pecks by individual insect.

Behavioral response measure 1: Search time. Grouping the eight conditions into four groups of two (as described above), overall mean search time for congruent trials was lowest $(16.68 \mathrm{~s} \pm 2.56 \mathrm{~s})$, followed by trails where prey was found alive $(23.95 \mathrm{~s} \pm 5.01 \mathrm{~s})$, prey found halved $(30.23 \mathrm{~s} \pm 5.38 \mathrm{~s})$, and prey found inert showed the highest mean search time $(32.32 \mathrm{~s} \pm 6.96 \mathrm{~s})$ (see Figure 3a). A within-subjects repeated measures ANOVA shows that these four grouped states (congruent, incongruent alive, incongruent halved, incongruent inert) show a significant effect for search time $(F(3,19)=2.950, p=$ 0.039). Pairwise comparisons of grouped state in this analysis show that there is no significant difference in search time variation between mealworms found incongruently alive and those in the other three grouped states (congruent, $p=0.154$; halved, $p=0.284$; inert, $p=0.172$ ). There is also no significant difference in search time variation between incongruent halved and incongruent inert conditions $(p=$ 0.762). Differences in search time variation between prey in a congruent state and prey found either halved $(p=0.017)$ or inert $(p=0.017)$ were significant.

Analyzing data by each of the 8 trial types individually, overall mean search time in congruent live-live trials was lowest $(15.64 \mathrm{~s} \pm 4.44 \mathrm{~s})$ whereas it was highest in incongruent live-half trials $(41.36 \mathrm{~s} \pm$ 9.59s), with the other 6 trial types ranging between those values (see Table 3 and Figure 3c). A withinsubjects repeated measures ANOVA looking at search time as the dependent variable shows that mealworm state is a significant effect across individual conditions $(F(1,7)=2.738, p=0.014)$. Pairwise comparisons of these 8 trial types (live-live, live-dead, live-half, dead-dead, dead-live, dead-half, livestick, stick-live) in this analysis show that there is a significant difference in search time variation between the live-live condition and each of the following: live-dead $(p=0.042)$, live-half $(p=0.015)$ and live-stick $(p=0.036)$. There were also significant differences between life-half and each of the following: dead-dead $(p=0.036)$, dead-live $(p=0.042)$, and dead-half $(p=0.154)$ (see Table 3$)$. The remainder of comparisons between conditions was not significantly different $(p>0.05)$ (see Table 3$)$. 

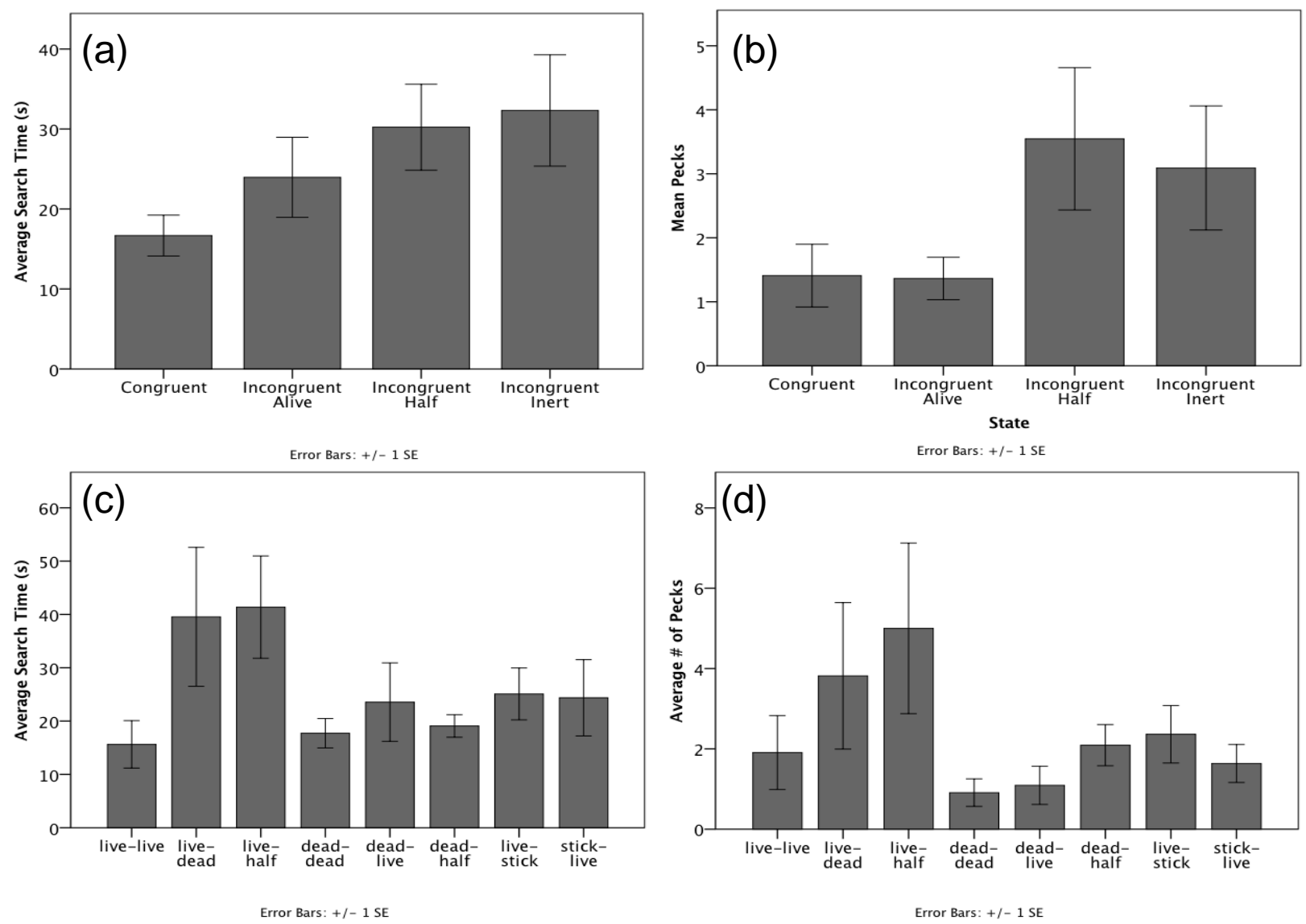

Figure 3. Experiment 2 (Prey animacy) - Average response in search and attendance time and number of pecks.

Table 3

Experiment 2: Search Time Mean and Significance (p-values) Between Conditions

\begin{tabular}{|c|c|c|c|c|c|c|c|c|c|}
\hline & $\begin{array}{l}\text { Mean } \\
\text { Search } \\
\text { Time (s) }\end{array}$ & $\begin{array}{l}\text { Live- } \\
\text { Live }\end{array}$ & $\begin{array}{l}\text { Live- } \\
\text { Dead }\end{array}$ & $\begin{array}{l}\text { Live- } \\
\text { Half }\end{array}$ & $\begin{array}{l}\text { Dead- } \\
\text { Dead }\end{array}$ & $\begin{array}{l}\text { Dead- } \\
\text { Live }\end{array}$ & $\begin{array}{l}\text { Dead- } \\
\text { Half }\end{array}$ & $\begin{array}{l}\text { Live- } \\
\text { Stick }\end{array}$ & $\begin{array}{l}\text { Stick- } \\
\text { Live }\end{array}$ \\
\hline Live-Live & $\begin{array}{l}15.64 \\
\pm 4.44\end{array}$ & & & & & & & & \\
\hline Live-Dead & $\begin{array}{l}39.55 \\
\pm 13.02\end{array}$ & $.042 *$ & & & & & & & \\
\hline Live-Half & $\begin{array}{l}41.36 \\
\pm 9.59\end{array}$ & $.015^{*}$ & .888 & & & & & & \\
\hline Dead-Dead & $\begin{array}{l}17.73 \\
\pm 2.75\end{array}$ & .687 & .114 & $.036 *$ & & & & & \\
\hline Dead-Live & $\begin{array}{l}23.55 \\
\pm 7.36\end{array}$ & .227 & .135 & $.042 *$ & .499 & & & & \\
\hline Dead-Half & $\begin{array}{l}19.09 \\
\pm 2.12\end{array}$ & .514 & .149 & $.031 *$ & .636 & .590 & & & \\
\hline Live-Stick & $\begin{array}{l}25.09 \\
\pm 4.86\end{array}$ & $.036^{*}$ & .200 & .088 & .227 & .769 & .312 & & \\
\hline Stick-Live & $\begin{array}{l}24.36 \\
\pm 7.15\end{array}$ & .124 & .131 & .100 & .425 & .883 & .480 & .909 & \\
\hline
\end{tabular}


Rather than grouping the 8 trial types simply into congruent ( 2 conditions) and incongruent (6 conditions), the third analysis groups trial types by congruent/positively incongruent ( 4 conditions: livelive, dead-dead, dead-live, stick-live), and negatively incongruent (4 conditions: live-half, dead-half, livedead, live-stick). Mean search time overall for 'congruent/positively incongruent' trials was less on average $(20.32 \mathrm{~s} \pm 2.83 \mathrm{~s})$ than for 'negatively incongruent' trials $(31.27 \mathrm{~s} \pm 4.35 \mathrm{~s})$. A within-subjects repeated measures ANOVA shows a significant effect between these two groups of conditions $(F(1,43)=$ 7.790, $p=0.008)$.

Behavioral response measure 2: Pecking frequency. Analyzing trial type groups of 4 (as described above, $\mathrm{N}=22$ ), overall mean pecking frequency for conditions where prey was found alive was lowest ( $1.36 \pm 0.33$ pecks), followed by congruent trials ( $1.41 \pm .49$ pecks), prey found inert (3.09 \pm 0.97 pecks), and prey found halved showed the highest mean search time ( $3.55 \pm 1.11$ pecks) (see Figure $3 \mathrm{~b})$. A within-subjects repeated measures ANOVA looking at pecking frequency as the dependent variable shows that for these four grouped states (congruent, incongruent alive, incongruent halved, incongruent inert) there is no significant effect $(F(3,19)=2.622, p=0.058)$. Pairwise comparisons of grouped state in this analysis show that there is no significant difference in pecking frequency variation between congruent conditions and those found alive $(p=0.931)$ or halved $(p=0.069)$, but does find a significant difference between congruent trials and incongruent inert conditions, $(p=0.019)$. There were also no significant differences in pecking frequency variation between incongruent alive and both halved $(p=0.077)$ and inert conditions $(p=0.080)$, or between halved and inert conditions $(p=0.726)$.

Analyzing data by each of the 8 trial types individually, overall mean pecking frequency in congruent dead-dead trials was lowest $(0.91 \pm 0.34$ pecks $)$ whereas it was highest in incongruent live-half trials $(5.00 \pm 2.12$ pecks), with the other 6 trial types ranging between those values (see Table 4 and Figure 3d). A within-subjects repeated measures ANOVA shows there is no significant effect across individual conditions $(F(1,7)=1.967, p=0.014)$ for pecking. Pairwise comparisons of these 8 trial types (live-live, live-dead, live-half, dead-dead, dead-live, dead-half, live-stick, stick-live) in this analysis show that there is a significant difference in search time variation between the dead-dead condition and each of the following: dead-half $(p=0.040)$, live-stick $(p=0.024)$ and stick-live $(p=0.024)$. There were no other significant differences in variation between individual conditions altering mealworm state (see Table 4).

Table 4

Experiment 2: Pecking Frequency Mean and Significance (p-values) Between Conditions

\begin{tabular}{|c|c|c|c|c|c|c|c|c|c|}
\hline & $\begin{array}{l}\text { Mean } \\
\text { Pecking } \\
\text { Frequency } \\
\text { (pecks) }\end{array}$ & $\begin{array}{l}\text { Live- } \\
\text { Live }\end{array}$ & $\begin{array}{l}\text { Live- } \\
\text { Dead }\end{array}$ & $\begin{array}{l}\text { Live- } \\
\text { Half }\end{array}$ & $\begin{array}{l}\text { Dead- } \\
\text { Dead }\end{array}$ & $\begin{array}{l}\text { Dead- } \\
\text { Live }\end{array}$ & $\begin{array}{l}\text { Dead- } \\
\text { Half }\end{array}$ & $\begin{array}{l}\text { Live- } \\
\text { Stick }\end{array}$ & $\begin{array}{l}\text { Stick- } \\
\text { Live }\end{array}$ \\
\hline Live-Live & $\begin{array}{l}1.91 \\
\pm 0.92\end{array}$ & & & & & & & & \\
\hline Live-Dead & $\begin{array}{l}3.82 \\
\pm 1.82\end{array}$ & .152 & & & & & & & \\
\hline Live-Half & $\begin{array}{l}5.00 \\
\pm 2.12\end{array}$ & .188 & .648 & & & & & & \\
\hline Dead-Dead & $\begin{array}{l}0.91 \\
\pm 0.34\end{array}$ & .169 & .106 & .084 & & & & & \\
\hline Dead-Live & $\begin{array}{l}1.09 \\
\pm 0.48\end{array}$ & .419 & .153 & .108 & .756 & & & & \\
\hline Dead-Half & $\begin{array}{l}2.09 \\
\pm 0.51\end{array}$ & .846 & .337 & .130 & $.040 *$ & .161 & & & \\
\hline Live-Stick & $\begin{array}{l}2.36 \\
\pm 0.72\end{array}$ & .620 & .427 & .253 & $.024 *$ & .147 & .706 & & \\
\hline Stick-Live & $\begin{array}{l}1.64 \\
\pm 0.47\end{array}$ & .661 & .164 & .152 & $.024 *$ & .311 & .424 & .278 & \\
\hline
\end{tabular}


Again, instead of grouping the 8 trial types into congruent ( 2 conditions) and incongruent (6 conditions), the third analysis groups trial types by congruent/positively incongruent (4 conditions: livelive, dead-dead, dead-live, stick-live), and negatively incongruent (4 conditions: live-half, dead-half, livedead, live-stick). Mean pecking frequency overall for 'congruent/positively incongruent' trials was less on average ( $1.39 \pm 0.29$ pecks $)$ than for 'negatively incongruent' trials ( $3.32 \pm 0.73$ pecks $)$. A within-subjects repeated measures ANOVA shows a significant effect between these two groups of conditions $(F(1,43)=$ 7.790, $p=0.008)$.

Prey destination. Taken together, the prey destination - whether it was eaten, taken away for caching or provisioning, or left in the experimental box - played a significant role in the response duration, and much longer response durations when the worm was eaten immediately. An ANOVA was used to compare means between conditions: prey was either eaten $(\mathrm{N}=87)$, taken away $(\mathrm{N}=17)$, or left in the box $(\mathrm{N}=6)$. Trials where there was no prey found were not included. On average, there was more search time and pecking when prey was consumed $(\mathrm{ST}=28.67 \mathrm{~s} \pm 2.54 \mathrm{~s}, \mathrm{PF}=2.89 \pm 0.46$ pecks $)$ than when prey was taken away $(\mathrm{ST}=7.41 \mathrm{~s} \pm 2.45 \mathrm{~s}, \mathrm{PF}=1.41 \pm 0.48$ pecks $)$ or left $(\mathrm{ST}=9.67 \mathrm{~s} \pm 5.21 \mathrm{~s}, \mathrm{PF}=$ $0.33 \pm 0.21$ pecks). When examining prey destination across all congruent and incongruent trials in both experiments, these differences appeared significant search time $(F(2,107)=8.238, p<0.001)$, but not pecking frequency $(F(2,107)=2.030, p=0.136)$.

\section{Discussion}

The data from this study revealed salient information about the North Island robin with respect to prey animacy but not type. According to Hunt et al. (2008), robins searched longer after finding only a fraction of the worms placed in a VoE box (e.g., four placed inside, and robins found two), and in Experiment 1, we confirmed that robins also search longer when no insect was found (incongruent) after seeing one dropped into the box. In terms of prey type, robins did not show significant differences in search time between individual insect types - for example, the difference in search times were not significantly longer on average for locusts than for earthworms. While the physical features of these insects varied - requiring different hunting and caching strategies (Menzies \& Burns, 2008) - this and other caloric, environmental or physiological details appear not to have influenced decision-making enough for a clear preference to emerge in robins' comparative search times. Robins did not preferentially search longer for one type of insect over another. Robins did however, clearly respond to the basic premise of VoE, and searched for significantly longer when food of any type disappeared unexpectedly.

In Experiment 2, robins searched and pecked significantly more after negatively incongruent outcomes (live-half, dead-half, live-dead, live-stick), than congruent and positively incongruent outcomes (live-live, dead-dead, dead-live, stick-live) overall. Breaking down those broader groups into four groups of two conditions each - congruent (live-live, dead-dead), incongruently found alive (dead-live, sticklive), incongruently found halved (live-half, dead-half), and found inert (live-dead, live-stick), we see that significant differences in search time appear more specifically between congruent \& halved, congruent $\&$ inert (and in pecking only between congruent \& inert). Looking in further detail across all eight conditions individually, live-dead and live-half and live-stick conditions all resulted in significantly longer search times than live-live; and search times after live-half presentations were significantly longer than dead-dead, dead-live, dead-half. While the latter can potentially be partially explained by volumetric differences (half a worm compared to a whole living worm) in addition to state, it doesn't work as a sole explanation for conditions where half a worm is found, as search times for dead-half are significantly lower than those for live-half. Simply following a rule that if a living worm goes missing an individual should search longer would explain most of the results, but not the full picture. It remains unclear why subjects don't search any longer when they find a stick after seeing a living worm than they do after finding the worm itself, but when they unexpectedly find half a worm or a whole dead worm, they search significantly longer. While it does appear that on the whole, robins do recognize and respond with differential search times to differences in prey state, but a clear pattern as to exactly when, how or why 
has yet to emerge.

When both experiments are taken together, robins spent significantly longer searching after immediately consuming prey compared to the fewer trials where prey was taken away (for cache or provisioning) or left in the box. While leaving the test site to provision could have reduced response times in that condition by making robins less likely to re-approach, robins were allowed to re-approach and reexamine the test site and re-examine after having cached if they returned within 20 seconds. In almost all cases the bird re-approached, and did so well within this time-frame. Because prey was consumed in the vast majority of instances ( 87 of 110 trials), the length of search time may not remain such a significant factor when samples are more balanced.

Given the nature of caching highly perishable food such as insects, a keen response to what state prey is hidden in, as well as when that state changed (prey stunned or killed) could be a vital aspect of hunting and caching strategy for a species like North Island robins. Alexander et al. (2005) observed that when robins are caching, prey is frequently injured but not killed. Whether this is accidental, or intentional, is unclear, but as a caching strategy, it is beneficial for storing highly perishable food, as already dead prey will spoil faster. A battery of experiments show that Scrub Jays are sensitive to exactly these types of features - the perishability and point in time a food item was stored (Clayton \& Dickinson, 1998, 1999), and additionally whether and which conspecifics were watching (Dally, Emery, \& Clayton, 2005; Emery \& Clayton, 2004), as well as the length of time lapsed between storing and re-accessing a given cache.

Robins' natural diet includes a wide variety of invertebrates (Menzies \& Burns, 2008), including slugs, stick insects (Phasmatodea) (Jewell \& Brock, 2002), earthworms (Lumbricidae) (Lee \& Zelanda, 1959), and weta (Orthoptera: Anostostomatidae) (Gibbs, 1998), among others; even prey larger or heavier than itself (Daugherty, Gibbs, \& Hitchmough, 1993; Powlesland, 1981). The mealworms presented here in Experiment 2, and certain conditions in Experiment 1, are not part of the North Island robin's natural diet, and the insects presented comprise a limited array of items. A broad assessment of preference for a naturally encountered prey, in relation to size (dimensions and volume), features (exoskeleton, limbs, defen ses), color and other variables would provide a more detailed understanding of which factors are key to robins' prey selection and foraging strategy.

Whether robins' pattern of longer search response after finding unexpected dead, partial or inanimate items is indicative of a broader suite of behaviors that applies to more abstract tasks (points of light or 2D animations), or whether it fits into a more basic search rule based simply on movement or absence/presence of prey, is something that needs further investigation. While motion appears to be a natural category for trained pigeons in that they can discriminate between video footage of moving and non-moving pigeons using only motion as a cue (Dittrich \& Lea, 1993), only some pigeons appear able to transfer the ability to discriminate biological motion (walking, pecking) onto displays of points of light as well (Dittrich, Lea, Barrett, \& Gurr, 1998). It is clear that motion and sound are highly likely to be key factors in insect foraging through leaf litter in the case of robins (Menzies \& Burns, 2008), but further investigation is needed to better understand whether these or other more specifically animacy-related features might also be used when robins are paralyzing and storing prey - and when robins are responding to potential pilferage. Testing larger populations, in a variety of environments (low human-contact, high human-contact, predator-free, predator-inhabited) is also important to creating a broader, more accurate picture of robins' responses to animacy and agency as a whole.

The present study provides a first start for developing a more detailed understanding of New Zealand robin's caching strategies and decision-making within the context of prey movement and state. The North Island robins' sensitivity to differing states of animacy in prey sheds light on salient visual information that may be attended to even in tasks aimed at other cognitive domains, such as numerosity or spatial memory. Additional follow-up tasks such as presentation of virtually animated movement, or conditions where insects are not manipulated by experimenters might be revealing of how generalizable such behaviors are, or whether recognition of self-propulsion vs. causal motion plays a role in caching and cache protection strategy as it relates to the animacy and therefore decay of such perishable prey. 


\section{Acknowledgements}

We would like to thank the staff and volunteers at Zealandia Sanctuary in Wellington for their support.

\section{References}

Addessi, E., Crescimbene, L., \& Visalberghi, E. (2008). Food and token quantity discrimination in capuchin monkeys (Cebus apella). Animal Cognition, 11, 275-282.

Agrillo, C., Dadda, M., \& Bisazza, A. (2007). Quantity discrimination in female mosquitofish. Animal Cognition, 10, 63-70. doi: 10.1007/s10071-006-0036-5

Agrillo, C., Dadda, M., Serena, G., \& Bisazza, A. (2008). Do fish count? Spontaneous discrimination of quantity in female mosquitofish. Animal Cognition, 11, 495-503. doi: 10.1007/s10071-008-0140-9

Alexander, L., Duthie, C., Fyfe, J., Haws, Z., Hunt, S., Montoya, I., \& Van Horik, J. (2005). An experimental evaluation of food hoarding by North Island robins (Petroica australia longipes). Notornis, 52, 138.

Armstrong, N., Garland, A., \& Burns, K. C. (2012). Memory for multiple cache locations and prey quantities in a food-hoarding songbird. Frontiers in Psychology, 3(584).

Barrett, H. C. (2005). Adaptations to predators and prey. In D.M. Buss (Ed.), The handbook of evolutionary psychology (pp. 200-223). New Jersey: John Wiley \& Sons.

Barrett, H. C., \& Behne, T. (2005). Children's understanding of death as the cessation of agency: A test using sleep versus death. Cognition, 96, 93-108.

Beran, M. J. (2001). Summation and numerousness judgments of sequentially presented sets of items by chimpanzees (Pan troglodytes). Journal of Comparative Psychology, 115, 181-191.

Beran, M. J. (2007). Rhesus monkeys (Macaca mulatta) enumerate large and small sequentially presented sets of items using analog numerical representations. Journal of Experimental Psychology: Animal Behavior Processes, 33, 42-54.

Beran, M. J., Evans, T. A., \& Hoyle, D. (2011). Numerical judgments by chimpanzees (Pan troglodytes) in a token economy. Journal of Experimental Psychology: Animal Behavior Processes, 37, 165.

Berrow, S. D., Kelly, T. C., \& Myers, A. A. (1992). The mussel caching behaviour of hooded crows Corvus corone cornix. Bird Study, 39, 115-119.

Biro, S., \& Leslie, A. M. (2007). Infants' perception of goal- directed actions: development through cue- based bootstrapping. Developmental science, 10(3), 379-398.

Bluff, L. A., Weir, A. A. S., Rutz, C., Wimpenny, J. H., \& Kacelnik, A. (2007). Tool-related cognition in New Caledonian crows. Comparative Cognition \& Behaviour Review, 2, 1-25.

Bugnyar, T., Stoewe, M., \& Heinrich, B. (2007). The ontogeny of caching in ravens, Corvus corax. Animal Behaviour, 74, 757-767.

Burns, K. C., \& Van Horik, J. (2007). Sexual differences in food re-caching by New Zealand robins Petroica australis. Journal of Avian Biology, 38, 394-398.

Carey, S. (2009). The origin of concepts. Oxford, UK: Oxford University Press.

Chen, M. K., Lakshminarayanan, V., \& Santos, L. R. (2006). How basic are behavioral biases? Evidence from capuchin monkey trading behavior. Journal of Political Economy, 114, 517-537.

Clara, E., Regolin, L., Vallortigara, G., \& Rogers, L. J. (2009). Chicks prefer to peck at insect-like elongated stimuli moving in a direction orthogonal to their longer axis. Animal Cognition, 12, 755-765.

Clayton, N. S., \& Dickinson, A. (1998). Episodic-like memory during cache recovery by scrub jays. Nature, 395, 272-274.

Clayton, N. S., \& Dickinson, A. (1999). Scrub jays (Aphelocoma coerulescens) remember the relative time of caching as well as the location and content of their caches. Journal of Comparative Psychology, 113, 403416.

Clayton, N. S., Emery, N. J., \& Dickinson, A. (2006). The rationality of animal memory: Complex caching strategies of western scrub jays. In S. L. Hurley \& M. Nudds (Eds.), Rational animals? (pp. 197-216). New York: Oxford University Press.

Collopy, M. W. (1977). Food caching by female American kestrels in winter. Condor, 63-68.

Csibra, G., \& Gergely, G. (1998). The teleological origins of mentalistic action explanations: A developmental hypothesis. Developmental Science, 1, 255-259.

Csibra, G., Gergely, ，O., \& Brockbank, M. (1999). Goal attribution without agency cues: The perception of 'pure reason' in infancy. Cognition, 72, 237-267. 
Dadda, M., Piffer, L., Agrillo, C., \& Bisazza, A. (2009). Spontaneous number representation in mosquitofish. Cognition, 112, 343-348.

Dally, J. M., Emery, N. J., \& Clayton, N. S. (2005). Cache protection strategies by western scrub-jays, Aphelocoma californica: Implications for social cognition. Animal Behaviour, 70, 1251-1263.

Daugherty, C. H., Gibbs, G. W., \& Hitchmough, R. A. (1993). Mega-island or micro-continent? New Zealand and its fauna. Trends in Ecology \& Evolution, 8, 437-442.

Dittrich, W. H., \& Lea, S. E. G. (1993). Motion as a natural category for pigeons: Generalization and a featurepositive effect. Journal of the Experimental Analysis of Behaviour, 59, 115.

Dittrich, W. H., Lea, S., Barrett, J., \& Gurr, P. (1998). Categorization of natural movements by pigeons: Visual concept discrimination and biological motion. Journal of the Experimental Analysis of Behaviour, 70, 281.

Emery, N. J., \& Clayton, N. S. (2004). Comparing the complex cognition of birds and primates. In L. J. Rogers \& G. Kaplan (Eds.), Comparative vertebrate cognition (pp. 3-55). London: Springer.

Garland, A., Low, J., \& Burns, K. C. (2012). Large quantity discrimination by North Island robins (Petroica longipes). Animal Cognition, 15, 1129-1140.

Gergely, G., \& Csibra. G. (2003). Teleological reasoning in infancy: The one-year-olds' naive theory of rational action. Trends in Cognitive Sciences, 7, 287-292.

Gibbs, G. W. (1998). New Zealand weta. Auckland, New Zealand: Reed Publishing.

Gobbini, M. I., Gentili, C., Ricciardi, E., Bellucci, C., Salvini, P., Laschi, C., \& Pietrini, P. (2011). Distinct neural systems involved in agency and animacy detection. Journal of Cognitive Neuroscience, 23, 1911-1920.

Guajardo, J. J., \& Woodward, A. L. (2004). Is agency skin deep? Surface attributes influence infants' sensitivity to goal-directed action. Infancy, 6, 361-384.

Heinrich, B., \& Pepper, J. W. (1998). Influence of competitor on caching behavior in the common raven (Corvus corax). Animal Behaviour, 56, 1083-1090.

Holthuijzen, A. M. (1990). Prey delivery, caching, and retrieval rates in nesting prairie falcons. Condor, 92, 475484.

Hunt, S., Low, J., \& Burns, K. C. (2008). Adaptive numerical competency in a food-hoarding songbird. Proceedings of the Royal Society B: Biological Sciences, 275, 2373-2379.

James, P. C., \& Verbeek, N. A. (1985). Clam storage in a northwestern crow (Corvus caurinus): Dispersion and sequencing. Canadian Journal of Zoology, 63, 857-860.

Jewell, T., \& Brock, P. D. (2002). A review of the New Zealand stick insects: New genera and synonymy, keys, and a catalogue. Journal of Orthoptera Research, 11, 189-197.

Johansson, G. (1973). Visual perception of biological motion and a model for its analysis. Attention, Perception, \& Psychophysics, 14, 201-211.

Kenward, B., Rutz, C., Weir, A. A., \& Kacelnik, A. (2006). Development of tool use in New Caledonian crows: inherited action patterns and social influences. Animal Behaviour, 72(6), 1329-1343.

Korpimaki, E. (1987). Prey caching of breeding Tengmalm's owls Aegolius funereus as a buffer against temporary food shortage. Ibis, 129(s2), 499-510.

Lee, K. E., \& Zelanda, N. (1959). The earthworm fauna of New Zealand. Department of Scientific and Industrial Research Wellington, New Zealand.

Mascalzoni, E., Regolin, L., \& Vallortigara, G. (2010). Innate sensitivity for self-propelled causal agency in newly hatched chicks. Proceedings of the National Academy of Sciences, 107, 4483-4485.

Meltzoff, A. N., \& Keith Moore, M. (1994). Imitation, memory, and the representation of persons. Infant behavior and development, 17(1), 83-99.

Menzies, I. J., \& Burns, K. C. (2008). Food hoarding in the New Zealand robin: A review and synthesis. In E. A. Weber \& L. H. Krause (Eds.), Animal behaviour: New research. New York: Nova Science Publishers.

O'Connell, S., \& Dunbar, R. I. M. (2005). The perception of causality in chimpanzees (Pan spp.). Animal Cognition, $8,60-66$.

Oksanen, T., Oksanen, L., \& Fretwell, S. D. (1985). Surplus killing in the hunting strategy of small predators. American Naturalist, 126, 328-346.

Powlesland, R. G. (1980). Food-storing behaviour of the south island robin. Mauri ora, 8, 11-20.

Powlesland, R. G. (1981). The foraging behaviour of the south island robin. Notornis, 28, 89-102.

Perdue, B. M., Talbot, C. F., Stone, A. M., \& Beran, M. J. (2012). Putting the elephant back in the herd: Elephant relative quantity judgments match those of other species. Animal Cognition, 15,1-7.

Rakison, D. H., \& Poulin-Dubois, D. (2001). Developmental origin of the animate-inanimate distinction. Psychological Bulletin, 127, 209. 
Rugani, R., Regolin, L., \& Vallortigara, G. (2011). Summation of large numerousness by newborn chicks. Frontiers in Psychology, 2, 1-8.

Santos, L. R., Barnes, J. L., \& Mahajan, N. (2005). Expectations about numerical events in four lemur species (Eulemur fulvus, Eulemur mongoz, Lemur catta, and Varecia rubra). Animal Cognition, 8, 253-262.

Scholl, B. J., \& Tremoulet, P. D. (2000). Perceptual causality and animacy. Trends in Cognitive Sciences, 4, 299309.

Sherry, D. F. (1985). Food storage by birds and mammals. Advances in the Study of Behavior, 15, 88.

Solheim, R. (1984). Caching behaviour, prey choice and surplus killing by pygmy owls Glaucidium passerinum during winter, a functional response of a generalist predator. Annales Zoologici Fennici, 21, 301-308.

Spelke, E. S. (2000). Core knowledge. American Psychologist, 55, 1233-1243.

Spelke, E. S., \& Kinzler, K. D. (2007). Core knowledge. Developmental Science, 10, 89-96.

Taylor, A. H., Hunt, G. R., \& Gray, R. D. (2012). Context-dependent tool use in New Caledonian crows. Biology Letters, 8, 205-7. doi: 10.1098/rsbl.2011.0782

Taylor, A. H., Hunt, G. R., Holzhaider, J. C., \& Gray, R. D. (2007). Spontaneous metatool use by New Caledonian crows. Current Biology, 17, 1504-1507. doi: 10.1016/j.cub.2007.07.057

Uller, C., Jaeger, R., Guidry, G., \& Martin, C. (2003). Salamanders (Plethodon cinereus) go for more: Rudiments of number in an amphibian. Animal Cognition, 6, 105-112.

Vallortigara, G., Regolin, L., \& Marconato, F. (2005). Visually inexperienced chicks exhibit spontaneous preference for biological motion patterns. PLoS Biology, 3, e208.

Vander Wall, S. B. (1990). Food hoarding in animals. Chicago: University of Chicago Press.

Van Horik, J., \& Burns, K. C. (2007). Cache spacing patterns and reciprocal cache theft in New Zealand robins. Animal Behaviour, 73, 1043-1049.

Watve, M., Thakar, J., Kale, A., Puntambekar, S., Shaikh, I., Vaze, K., \& Paranjape, S. (2002). Bee-eaters (Merops orientalis) respond to what a predator can see. Animal Cognition, 5, 253-259.

Woodward, A. (1999). Infants' ability to distinguish between purposeful and non-purposeful behaviors. Infant Behavior and Development, 22, 145-160. 